\title{
Investigação para a paz: passado, presente e futuro'
}

\section{Peace Research: past, present and future}

Investigación para la paz: pasado, presente y futuro

- Filósofo, Matemático e Doutor em Sociologia

- Um dos principais pesquisadores dos Peace Studies Diretor da Lund University Peace Research Institute, Suécia (1971-80)

- $\quad$ Diretor da Copenhagen Peace Research Institute (COPRI), Dinamarca (1988-2001)

- Autor de "Ethnicity and Intra-State Conflict: Types, Causes and Peace Strategies". Aldershot: Ashgate, 1999. ix+327 pp, editado com Christian P. Scherrer; e de "Looking Back at the Year 2000: The People Were Right, The Experts Not". Special issue of FUTURES, vol. 35, no. 2 (March 2003) escrito com Johan Galtung; entre outras publicações.

- In memorian 


\section{Resumo}

0 percurso de afirmação da investigação para a paz como disciplina assinala diferentes momentos de crise de identidade, expressos em densos debates epistemológicos. Como resultado desse crescimento dilemático, a investigação para a paz continua hoje atravessada por três questões conformadoras essenciais que este texto procura delimitar. A primeira é a do alcance da sua orientação para valores e políticas concretas. A segunda é a do seu lugar num território cognitivo disputado. E a terceira é a da densidade conferida à não-violência nos processos de transformação política.

\section{PALAVRAS-CHAVE: INVESTIGAÇÃO PARA A PAZ • ESTUDOS PARA A PAZ • EPISTEMOLOGIA DA PESQUISA PARA A PAZ.}

\section{Abstract}

The affirmation pathway for investigating peace as a discipline shows different periods of identity crisis, expressed in extensive epistemological debates. Due to the growth of this dilemma, three structural and essential issues that this text seeks to delimit are in question in the investigation for peace. The first is the reach of its orientation for concrete values and policies. The second is the definition of its place in a disputed cognitive territory. And the third is the density of nonviolence in political transformation processes.

KEYWORDS: PEACE RESEARCH • PEACE STUDIES • PEACE RESEARCH EPISTEMOLOGY.

\section{Resumen}

El camino de consolidación de la disciplina sobre los estudios para la paz está marcado por varios momentos de crisis de identidad, en que se han manifestados profundos debates epistemológicos. Como resultado, en los estudios para la paz se encuentran hasta hoy tres temas elementales y esenciales, que en este texto se busca delimitarlos. El primer es la amplitud de su orientación para los valores y las políticas específicas. El segundo es su lugar en un campo cognitivo competitivo. Y el tercer es la magnitud establecida a la no-violencia en los procesos de cambios políticos. 
A expressão peace research, ou "investigação para a paz", vem sendo usada há cerca de meio século para designar os institutos e atividades existentes nesta área. 0 Instituto de Investigação para a Paz, de Oslo (PRIO), foi o primeiro a incluí-la no nome, não obstante sua criação ter sido precedida pela de um pequeno número de outros institutos. Tanto a expressão como aquilo que ela refere fazem-nos recuar cerca de vinte anos relativamente a esse momento. Com efeito, as primeiras propostas de criação de instituições destinadas àquilo a que se chamou "investigação para a paz" surgiram já antes do final da II Guerra Mundial. 0 mesmo pode afirmar-se com respeito às primeiras obras de alguns dos seus grandes fundadores, autores como Lewis Fry Richardson, Quincy Wright e Pitirim A. Sorokin. Muitas línguas traduzem diretamente a expressão, limitando-se a juntar as palavras "investigação" e "paz"; outras línguas utilizam uma ou outra versão do francês "polemologie", e algumas recorrem ainda a outras expressões. Há muitos institutos que ostentam, no respectivo nome, diferentes combinações dos termos "paz", "conflito", e outros mais.

Não haverá nunca um consenso universal em torno da expressão. Tanto "paz" (para já não falar em "segurança") como "investigação" são aquilo a que o filósofo Walter Bryce Gallie (1956) chamou de "conceitos essencialmente contestados", ou seja, conceitos relativamente aos quais não se chegará nunca a uma definição consensual a não ser no interior de comunidades extremamente reduzidas ou mesmo sectárias. As mais diferentes culturas - bem como as diferentes orientações políticas existentes dentro de cada cultura - usam o termo "paz" (traduzido da forma mais grosseira de umas línguas para as outras) para conotar diferentes combinações de valores, por sua vez sujeitas a diferentes ênfases relativas: ausência de guerra, bem-estar, justiça (divina), harmonia social, a paz interior de cada um etc. (Ishida, 1969; Galtung, 1981; Koppe, 2001). Quanto a "investigação", assistimos a diversas vagas de discussões - genéricas umas, outras especificamente relacionadas com as ciências sociais - em torno dos critérios (epistemologia, produção teórica, métodos empíricos etc.) a que uma atividade ou os respectivos resultados deveriam obedecer para serem considerados como "investigação" ou "científicos". De nenhuma delas resultou consenso entre a comunidade de estudiosos.

Uma terceira controvérsia data da década de 1960: quer-se dizer o quê, quando se junta "paz" e "investigação" numa única expressão? Muitas vezes interpreta-se como significando "investigação sobre a paz", indicando-se assim que deveria ser encarada como mais uma disciplina académica entre outras. "Investigação pela paz", por outro lado, tende a sublinhar uma orientação no sentido de determinados valores, como sucede com frequência em formulações utilizadas em congressos e em editoriais de revistas. Além da ambiguidade inerente à palavra "paz", há o risco de circularidade: para saber (mais do que adivinhar) qual a investigação que promove a paz, é necessário, antes, ter já alguma investigação com resultados concretos sobre o tema.

As várias discussões em torno do problema da definição dariam, por si só, para escrever um livro. Para os objetivos deste artigo, no entanto, o mais prático será proceder como se este versasse, por exemplo, a oncologia: partindo, para tanto, de noções já amplamente partilhadas por estudiosos que identifiquem-se como oncologistas - ou investigadores da paz-, em vez de atender ao modo como aqueles que, como tal, se não identificam, consideram que este campo de investigação deve ser definido. Há fatos relacionados com a investigação para a paz que só até certo ponto dependem das pequenas nuances de definição.

Se considerarmos a investigação para a paz da perspectiva da sociologia da ciência, e pensarmos concretamente naquilo que foi a sua institucionalização gradual, algumas das questões importantes a colocar dizem respeito aos números. Assim, é possível mantermo-nos inteirados da quantidade de institutos existentes e respectivos membros recorrendo aos diretórios da Unesco. Além disso, diversos autores, baseando-se em critérios ligeiramente diferentes entre si, elaboraram listas comentadas das revistas especializadas dedicadas à investigação para a paz (Chatfield, 1979; van den Dungen, 1981; Scharffenorth; Huber, 1983; Gleditsch, 1987). Ainda a título de exemplo, a International Peace Research Newsletter, a alemã AFB Information e as "newsletters" da Sociedade de Ciências da Paz mencionam, com regularidade, organizações profissionais de âmbito 
tanto nacional como internacional. Seja qual for o critério utilizado, o quadro resultante é, sempre, aproximadamente 0 mesmo: Há quarenta anos, a investigação para a paz era uma ideia nova que despontava para um futuro incerto, contando com alguns institutos e com um par de revistas especializadas e de associações internacionais acabadas de fundar. Há trinta anos, tínhamos centenas de institutos e dezenas de revistas, bem como um conjunto de associações e congressos de âmbito nacional e regional. Há vinte anos, todas estas realidades proliferavam em maior número ainda, contudo o período de crescimento rápido havia passado, e mesmo hoje a situação não é muito diferente. Com efeito, hoje em dia a investigação para a paz apresenta todos os sinais de haver atingido a maioridade, manifestada através de múltiplos exemplos: volumes em honra de alguns dos mais antigos estudiosos da área (ver Trittmann; Schmidt, 2002), bibliografias (entre cujos títulos clássicos se incluem Boulding, Passmore e Gassler [1979] e Wien [1981]), diretórios ([United Nations Educational, Scientific and Cultural Organization, 2000] - com anteriores edições a surgirem a intervalos de vários anos a partir de 1965), e publicações versando o historial destes estudos (van den Dungen [1977]; Boulding e Vayrynen [1979]; Wiberg [1988]; Koppe e Reichardt [1994]; Kodama [2004]).

Por trás da crueza dos números deparamo-nos uma história mais complexa. Os primeiros institutos apareceram, sobretudo, na região do Atlântico Norte protestante (Escandinávia, Holanda, Alemanha, Reino Unido, Estados Unidos da América). Quanto ao desenvolvimento posterior, ela apresenta duas vertentes principais: na verdade, ao mesmo tempo que naquela região se iam criando muitos institutos novos, certas tradições que vigoravam na investigação levada a cabo na América Latina (a tradição da "dependência" etc.), na Índia (a tradição gandhiana etc.), na Europa (a tradição marxiana etc.), no Japão (Hook; Kan, 1983) e noutros lugares começaram a identificar-se como sendo investigação para a paz e a marcar presença em associações, revistas e congressos. Esta natureza dupla do processo de crescimento teve consequências importantes.

\section{BREVE HISTÓRIA}

A história da investigação para a paz é, em grande medida, a história das suas crises; no entanto, é bom lembrar que, em chinês, o signo para "crise" consiste nos signos usados para dizer "perigo" e "oportunidade". Já escrevi, noutro local (Wiberg, 1995), que tivemos três grandes crises na investigação para a paz: por volta de 1970, de 1980 e de 1990. A primeira das crises teve a ver com o que seriam agendas legítimas com vista a essa investigação. A segunda crise, que em certa medida foi resultado da primeira, sobrepôs o alargamento do campo de investigação ao favorecimento exclusivo de uma das várias agendas então sobre a mesa: a investigação para a paz estava com problemas para encontrar um cerne bem definido e uma identidade clara. A terceira prendeu-se com o êxito daquilo que fora importante na agenda inicial da investigação para a paz e dela sempre fizera parte integrante: a ideia de transcender a Guerra Fria.

A primeira crise, ocorrida por volta de 1970, teve uma envolvência multifacetada. Entre os fatores extrínsecos contavam-se a guerra do Vietname e a invasão da Checoslováquia pela União Soviética, bem como os levantamentos nas universidades e as polémicas de natureza científica e académica que aí eclodiram, particularmente nas ciências sociais. Toda essa vasta realidade é, por vezes, designada sinteticamente pela expressão "1968". Entretanto, tivera já início o alargamento da investigação para a paz mediante a incorporação de novas tradições, incluindo de outras partes do mundo. A crise opôs os protagonistas da "velha agenda" (que estudava as causas da guerra, as dinâmicas armamentistas, os sistemas de paz etc.) à "nova agenda", que propunha debruçar-se sobre a exploração, a dominação e a dependência, o imperialismo etc. A discussão então havida (International Peace Research Association, 1970) foi - para usar um eufemismo - bastante acesa, com o segundo grupo a acusar a agenda antiga de fazer "investigação para a pacificação" (em vez de uma investigação de tipo emancipatório), "investigação liberal para a paz" (em vez de investigação crítica) etc., ao passo que alguns dos membros do primeiro grupo acusavam a parte contrária de promover a revolução armada em nome da paz. 


\section{ANO 15 • NÚMERO 28 • 1 SEM. 2018 • ORGANICOM}

INVESTIGAÇÃO PARA A PAZ: PASSADO, PRESENTE E FUTURO

A primeira crise produziu diversos resultados. 0 mais importante foi que, no que às agendas dizia respeito, a comunidade dos investigadores para a paz depressa se inclinou para uma solução de tipo copulativo ( $x$ e y), preterindo assim qualquer opção de tipo disjuntivo ( $x$ ou y). Frustrados pelo fato de restar ainda demasiado da agenda contrária, os representantes da "linha dura" de cada uma das agendas tenderam, então, a abandonar a investigação para a paz, porém a comunidade no seu todo acabou por expandir seus horizontes, como se pode verificar pelas agendas da investigação institucional, pelos programas e atas de congressos etc. Tal não se deveu a uma mera "coexistência pacífica" entre as agendas, mas antes, nalguns casos, a um fenômeno de sinergias bem-sucedidas. 0 programa estrutural de Johan Galtung englobava uma "teoria estrutural da violência", em que a noção de violência estrutural surgia em contraponto com "paz positiva(mente definida)", nessa altura uma expressão já firmada: se "paz negativa(mente definida)" é a ausência de guerra, aquela era entendida como a ausência de violência estrutural. Esta nova noção começou por ser trabalhada do ponto de vista conceitual e teórico, mas depressa se seguiram estudos empíricos, nos quais a violência estrutural era operacionalizada através do recurso a dados estatísticos sobre a expectativa de vida, mortalidade infantil etc. Uma outra obra de síntese foi a tese de doutoramento de Wallensteen(1973), um trabalho pioneiro em que se estabelecem relações empíricas entre as estruturas do comércio e as estruturas da guerra. Uma das conclusões principais desse trabalho foi que a tradicional convicção do pensamento liberal, segundo a qual o comércio fomenta a paz, era confirmada no caso de relações comerciais simétricas, enquanto a convicção inversa, associada à tradição leninista, encontra maior confirmação no caso de relações assimétricas.

De um modo geral, a crise acabaria por produzir efeitos benéficos: o período entre meados da década de sessenta e meados de setenta foi, de facto, uma época de crescimento rápido no que se refere ao número de instituições, revistas e investigadores do tema da paz. Por volta de 1975, tornara-se evidente que a investigação para a paz viera para ficar. 0 crescimento continuou durante a década seguinte, mas agora a um ritmo mais modesto, e ao mesmo tempo que uma segunda crise começava a desenhar-se.

Muito menos dramática que a primeira, a segunda crise não iria registar os mesmos confrontos espetaculares em congressos e nas páginas das revistas da área. Em grande medida, ela foi uma consequência da negociação bem-sucedida em que se traduziu a primeira crise e da agenda amplamente alargada e completa que desta resultara. Quem lhe definiu bem a essência foi Hylke Tromp, que foi o segundo professor e diretor do Polemologisch Instituut, em Groningen:

a investigação para a paz transformou-se naquilo que, na astronomia, se chama um buraco negro. Não parece existir problema social que, em última análise, não tenha o seu lugar legítimo dentro da investigação para a paz e que, por conseguinte, não seja absorvido pelos processos definidores dessa mesma investigação (Tromp, 1981, p.xxvii).

Tratou-se, em grande parte, de uma crise de identidade da investigação para a paz em geral, mas que se estendeu a muitos institutos em particular. 0 campo tornara-se tão vasto que se afigurava impossível a qualquer indivíduo isolado dominar toda a informação ou ir para além de contributos setoriais. Qualquer instituto que presuma abarcar a totalidade do campo da investigação para a paz arrisca-se a dispersar demasiado os seus recursos e a deixar de ser capaz de para ele contribuir de forma abalizada. Simplificando, digamos que é possível discernir dois tipos de institutos: aqueles cujo mandato e agenda eram, desde o início, razoavelmente limitados, e aqueles que tentaram reproduzir a agenda alargada da comunidade da investigação para a paz no seu conjunto. Entre estes últimos, alguns conseguiram enfrentar a crise estreitando o foco da sua investigação, assistindo-se à substituição da anterior multiplicidade de projetos por um número reduzido de grandes programas de investigação. Os institutos do primeiro tipo, ou que evoluíram nesse sentido, tenderam a sobreviver e a prosperar, ao passo que os do segundo tipo acabaram, frequentemente, por deparar com problemas, que nalguns casos se revelariam fatais. Entretanto, continuaram a criar-se institutos e o conjunto total dos recursos existentes e do número de investigadores continuou a aumentar durante a década de 1980, pelo que a segunda crise também acabaria por fazer mais bem do que mal à investigação para a paz. 
ANO 15 • NÚMERO 28 • 1은. 2018 • ORGANICOM

A terceira crise foi causada por um fator completamente exógeno: o fim da Guerra Fria, previsto por alguns - se bem que, normalmente, pelas razões erradas -, e com Galtung (cujo discurso no congresso da European Nuclear Disarmament (END) em Berlim, no ano de 1983, importa recordar [Galtung, 1980]) a ser uma das raras excepções. Este acontecimento gerou uma grande reflexão no interior de várias disciplinas: por quE a incapacidade de prevê-lo (Allan; Goldmann, 1995)? No que concretamente à investigação para a paz se referia, houve lugar a um debate interno acerca do caminho a seguir a partir de então: que tradições de investigação prosseguir e aprofundar? Que tópicos acrescentar à agenda (Wiberg, 1995)? Colocavamse também novas (ou velhíssimas) questões extrínsecas relativas à razão de ser e à identidade da investigação para a paz, 0 que em parte levou a travar "batalhas territoriais" com outras disciplinas.

\section{OS VALORES E A INVESTIGAÇÃO PARA A PAZ}

Um amplo consenso existente na investigação para a paz, pelo menos no plano dos princípios, diz respeito à orientação em função de valores. Uma série de editoriais do Journal of Peace Research (JPR) a partir de 1964, bem como reiteradas declarações emanadas da Associação Internacional de Investigação para a Paz (IPRA), vêm acentuando a ideia de que a investigação para a paz tem a ver com - ou tem por base - valores (ou, numa outra formulação ainda, é "orientada para políticas" concretas). Johan Galtung (1996) propõe uma epistemologia mais geral para essa ideia quando compara a investigação para a paz à arquitetura ou à medicina, por exemplo, cada uma das quais compreende um triângulo completo, composto por dados, teoria e valores (paz, saúde, beleza etc. - tornando-se de seguida necessário especificar cada um dos vários aspetos). Algumas áreas do direito, da ética ou da teologia ocupam-se de apenas um dos vértices: o das normas e valores. Certos domínios da ciência ou das ciências sociais centram-se exclusivamente num segundo vértice, desenvolvendo aspetos de conceptualização e de teoria, enquanto outras áreas se debruçam por inteiro sobre o terceiro vértice, coligindo e analisando dados ao mesmo tempo que creem ser outros a ficar com a especulação teórica ("creem", já que alguma teoria subjaz sempre às medições de que resultam os dados). Algumas atividades de investigação científica aliam dois vértices: assim, e por exemplo, os dados e a teoria contrapõem-se de diversas formas ("gerando", "confirmando/infirmando", ou "desenvolvendo" teoria; "afinando" medições); e por seu lado, os dados e as normas entram em relação sempre que um juiz ou juíza dá sua sentença sobre se 0 comportamento demonstrado pelos factos viola o corpus de normas jurídicas que é sua função ministrar. 0 modelo ideal de investigação para a paz apresentado por Galtung correlaciona os três vértices do triângulo: valores, teoria, e dados.

Isto, por sua vez, conduz-nos a dois conjuntos de questões apontadas em direções diferentes: por um lado, questões lógicas e epistemológicas que se prendem com as relações entre os valores e a investigação e, por outro lado, questões empíricas relativas ao trabalho concreto a que os investigadores da paz, efetivamente, se dedicam. A relação entre valores e investigação esteve presente nas diversas vagas em que o debate se processou, a primeira das quais ocorreu há um século. Nessa discussão participaram Windelband, Rickert, Dilthey e Weber, mantendo-se hoje ainda válidos muitos dos aspectos tratados. Uma segunda vaga está ligada à fase inicial do empirismo lógico das décadas de 1920 e 1930 (o "Círculo de Viena"), marcado pela ambição de purgar da linguagem científica, através da aplicação de critérios estritamente lógicos, toda e qualquer proposição metafísica e normativa. Algumas versões mais evoluídas desta posição reconheceriam que não é possível haver uma ciência absolutamente "livre de valores", num certo sentido que esta expressão carregada de ambiguidade comporta. Mas já é possível desenvolver uma metodologia capaz de reduzir os preconceitos inconscientes gerados pelos valores que cada investigador traz consigo, como de resto propõe a linha de investigação presente no trabalho de referência de Lewis Fry Richardson (1960). Outra posição, explanada por Gunnar Myrdal (1958), será fazer com que as premissas dos valores subjacentes a determinado estudo sejam explicitadas de forma tão clara que se torne possível verificar se as conclusões normativas decorrentes dos resultados da investigação estão em conformidade com tais premissas. Se não estiverem, é porque outros valores e premissas acabaram por se infiltrar, porventura de forma inconsciente, no esforço de investigação, tornando-se então importante descobrir quais são e de que modo terão enviesado todo o processo. 0 problema é, muitas 
vezes, mais difícil na prática do que na teoria: como sabemos quais as premissas dos valores com base nos quais agimos, e se fomos também capazes de expor de uma maneira aberta e exata as premissas incorporadas no conjunto de nossa análise?

A investigação feita sobre a própria investigação tem mostrado que é muito fácil os investigadores subestimarem a dificuldade que isto implica e sobrestimarem sua capacidade de refletirem sobre si mesmos. 0 problema não é, contudo, exclusivo da investigação para a paz, o que não será aqui aprofundado.

Quando diferentes culturas e correntes políticas diversas combinam valores de modos variados para nos dar a sua definição de "paz", não surpreende que também surjam diferenças entre a comunidade de investigadores. Há uma corrente que sempre identificou a "paz" como a "ausência de guerra", que afinal é o menor denominador comum dos conceitos de paz presentes nas diferentes culturas. Outros autores, na esteira de São Tomás de Aquino, Martin Luther King (1963) e outros, defenderam que esta visão é demasiado redutora e que a ocorrência da paz exige a presença de outros valores. À paz definida como ausência de algo (a guerra) chamou-se, tradicionalmente, "paz negativamente definida" - ou, de forma abreviada, "paz negativa" -, ao passo que a expressão "paz positiva" designava a paz definida pela presença de algo. Ambos os termos são infelizes, porquanto parecem comportar conotações valorativas, o que não seria sua intenção; no entanto acabaram por firmar-se. A lógica é, também, um pouco arbitrária: já aquando do debate ocorrido durante a primeira crise, os novos valores eram definidos de uma maneira ou de outra, ou seja, quer como presença (justiça social, liberdade), quer como ausência (de exploração, dependência e dominação). Desde a década de 1960, propuseram-se valores diversos para suprir a ausência da violência física; os principais candidatos, hoje em dia, parecem ser os seguintes: I) a equidade ou bem-estar (isto é, a ausência de uma violência estrutural); II) a liberdade (ausência de opressão); III) a identidade (ausência de alienação ou de violência cultural). 0 debate irá, por certo, manter-se, e para a pesquisa séria e competente não constituirá qualquer problema que diferentes programas de investigação se centrem em diferentes (combinações de) valores. Basta que cada programa explicite quais os valores que conota quando fala em "paz", quer dizer, quais as premissas dos valores em que se baseia. Não se pode dizer que a investigação na área da medicina tenha sofrido muito pelo facto de não haver uma definição exata e consensual do que é a "saúde".

Regressemos agora ao nosso triângulo fazendo outra pergunta: a que nível se deve funcionar? São muito poucos os estudiosos dotados da capacidade de Galtung para funcionar de maneira competente com os três vértices, pelo que não faz muito sentido usar este aspecto como critério para apurar se aquilo que um determinado estudioso está a fazer é investigação para a paz. Na maioria dos casos, impõe-se uma divisão implícita ou explícita do trabalho, em que alguns especialistas recolhem dados - por exemplo, para facultar uma base capaz de sustentar aferições normativas, ou para testar hipóteses - enquanto outros especialistas se ocupam do aprofundamento teórico e os generalistas procuram combinar os três vértices. 0 nível relevante, para uma "triangulação" deste tipo, pode ser portanto todo um programa de investigação situado num só instituto ou, inclusivamente, uma rede de estudiosos, de programas e de institutos trabalhando em colaboração, ainda que geograficamente dispersos.

\section{UMA INVESTIGAÇÃO ORIENTADA PARA POLÍTICAS CONCRETAS: MAS POLÍTICAS DE QUEM?}

Em vez de "orientada para valores", diz-se por vezes da investigação para a paz que é (ou que se esforça por ser) "orientada para políticas". Nos seus primeiros anos, o Journal of Peace Researchincentivava os autores a concluir os artigos com uma secção dedicada a recomendações concretas. Mas cedo a prática foi abandonada; acontece que ela se revelava amiúde extremamente artificial, quando era grande o fosso entre o tema em análise e as eventuais políticas a seguir: as recomendações ora tendiam a ter uma sustentação muito frágil na análise, ora necessitavam de muitas reservas no tocante à comparação das variáveis, 
ANO 15 • NÚMERO 28 • 1ํㅗ․ 2018 • ORGANICOM

INVESTIGAÇÃO PARA A PAZ: PASSADO, PRESENTE E FUTURO

e noutros casos ainda eram de tal modo abstratas que acabavam por se revelar pouco relevantes no respeitante às políticas efetivas. Por mais louvável que, em princípio, se afigure (Wiberg, 2003), a investigação em função de políticas concretas suscita diversos problemas. Um dos problemas é traduzido pela pergunta, "políticas de quem?" Uma resposta frequente é que se trata das "políticas dos decisores", querendo-se com isso, normalmente, significar tanto os governos e parlamentos ao nível nacional como as organizações de âmbito internacional. Tal resposta tem o mérito de ir diretamente àqueles que decidem em matéria de políticas, aspirando assumir o papel de assessores especializados; ela tem, contudo, algumas desvantagens. Uma das desvantagens é que pode suceder que o valor "paz" seja partilhado pelos decisores e, inclusivamente, mencionado especificamente pelo investigador, mas é pouco provável que esse seja seu único valor, sendo até frequente possuir uma prioridade mais baixa que outros valores. 0 investigador da paz pode, assim, estar a buscar respostas para outras perguntas que não aquelas que preocupam os decisores, os quais por sua vez poderão estar mais interessados na maneira de evitar uma dada ameaça ou obter este ou aquele ganho sem aumentar excessivamente o risco de guerra. Nalguns casos, como 0 das administrações dos Estados Unidos da América após a Guerra Fria, poderá até haver razões para suspeitar que a guerra era exatamente o objetivo pretendido, e sob vários pretextos; nesse contexto, afigura-se fútil qualquer aconselhamento no sentido de a evitar.

As situações decisórias com que se confrontam os governos e órgãos afins caracterizam-se, frequentemente, por aquilo a que o sociólogo sueco Johan Asplund (1979) chamou de "ignorância precária": essas entidades sabem que sabem muito pouco, ao mesmo tempo que a decisão tomada, seja qual for, pode trazer consequências desastrosas. Torna-se então importante, para acautelar futuros álibis políticos, que haja unanimidade entre os especialistas; os que são consultados a título oficial tendem, à partida, a ser selecionados com vista a obter-se essa unanimidade. Falando, em certa ocasião, a uma plateia em Lund, na Suécia, Hans Morgenthau contou que, quando se dirigia para a sua primeira reunião na Casa Branca na qualidade de novo conselheiro da administração Kennedy, disse a um amigo que já ali trabalhava que havia preparado diversas medidas políticas em alternativa, obtendo como resposta que estava completamente enganado quanto à tarefa que dele se esperava, uma vez que o seu trabalho era eliminar alternativas, não engendrá-las.

Um outro problema se coloca no que toca ao acesso aos decisores: habitualmente é dado como assente que, para fazer passar qualquer mensagem, há que "falar a linguagem deles", ou - para usar uma terminologia mais recente - "cingir-se ao discurso dominante". O problema com isto é que esse discurso dominante pode ter laivos do "newspeak" orwelliano (Orwell, 1949), sendo construído de maneira tal que, se alguém lhe questionar os pressupostos básicos, arriscar-se-á a parecer ignorante, incoerente, ou imoral. Nos casos mais graves, "falar a linguagem deles" deixa pouco de significativo para ser dito, quer isso se fique a dever a processos complexos, quer resulte de uma manipulação das mensagens ditada pela obtenção dos objetivos pretendidos. Uma tese central, presente já em Berger e Luckmann (1966), capta o essencial da ideia de Orwell: o poder é definir a realidade.

Uma alternativa a "falar a linguagem deles" é verter os resultados da investigação em respeitável estilo académico, com todas as reservas e restrições necessárias para que se não diga mais do que aquilo que pode ser afirmado em base sólida. Mas os decisores raramente dispõem de tempo para ler - e se leem, é o tipo de escrita produzida por jornalistas assoberbados com trabalho e sujeitos a prazos apertados e a normas profissionais estritas quanto ao que constitui "notícia".

Tudo isto são problemas, mas não são problemas insuperáveis: alguns investigadores poderão até, eventualmente, possuir uma mensagem a que os decisores sejam receptivos, bem como o conjunto de atributos necessários para a fazer passar. Muitos outros tentarão outra via para veicular suas recomendações quanto às políticas a adotar, preferindo dirigir-se às forças da oposição, aos movimentos para a paz e a outras organizações não governamentais ou à opinião pública em geral em vez de tentarem furar as barreiras das assessorias e de todos os controlos de que se fazem rodear os poderes vigentes. Isto pode reduzir o problema do acesso, mas por certo que o não elimina: os grandes meios de comunicação de massas, e 


\section{ANO 15 • NÚMERO 28 • 1오. SEM. 2018 • ORGANICOM}

INVESTIGAÇÃO PARA A PAZ: PASSADO, PRESENTE E FUTURO

muito particularmente a televisão, também têm seus controles (os "gatekeepers"); pode igualmente reduzir a dificuldade que é fazer passar os resultados da investigação, mas as organizações para a paz, bem como os partidos políticos etc., não diferem grandemente dos Ministérios dos negócios estrangeiros: é frequente terem suas próprias ortodoxias, ainda que de conteúdo diverso ou mesmo contrário. No entanto, estas entidades podem revelar-se menos irredutíveis, mais maleáveis, possibilitando a criação de algo próximo daquilo a que Habermas chama a situação de diálogo ideal, em que o que conta são os argumentos e não o poder. Neste caso, o papel continua a ser o de conselheiro, se bem que o destinatário seja mais empático e mais receptivo.

0 investigador pode também ir para além deste papel, trabalhando com a - ou até na - organização a que a recomendação é feita. Nesse caso, são necessárias capacidades intelectuais e competências sociais adicionais, no entanto são muitos os exemplos bem-sucedidos que é possível referir. A Transcend, organização encabeçada por Johan Galtung, dirige uma universidade "on-line" e faz consultoria em muitos conflitos por todo o mundo. A Fundação Transnacional para os Estudos sobre a Paz e o Futuro (Transnational Foundation for Peace and Future Research, TFF), sediada em Lund, dirige uma página eletrónica com milhares de acessos diários e já prestou serviços de consultoria em diversos conflitos. 0 projeto Incore, da Universidade do Ulster, granjeou reputação à escala global por aliar análises e consultorias de reconhecida qualidade científica.

Aí levantam-se novos problemas: será possível ser, ao mesmo tempo, político (porventura num sentido amplo do termo) e cientista? Max Weber (1919a, 1919b) defendia que se trata de vocações diferentes, com regras tão diferentes que dificilmente é possível conciliá-las, e a verdade é que ninguém o refutou de forma convincente. Uma solução poderá ser, então, alternar entre um papel e outro, em vez de tentar em vão assumi-los em simultâneo; um problema que esta solução suscita é que as pessoas que andam há muito na política poderão achar difícil readaptar-se àquilo que, segundo as normas muito mais restritivas do mundo académico, constitui um argumento respeitável, uma prova relevante, uma lógica vinculativa etc. Mas um consultor competente pode, desde que seja capaz de manter algum distanciamento, servir de intermediário ou "tradutor" entre o mundo do estudioso e o mundo da política.

Outro papel alternativo será o de Cassandra. Homero conta que os deuses haviam concedido a Cassandra o dom de prever 0 futuro, se bem que acompanhado da maldição que era o facto de ninguém nela acreditar. Suas previsões sobre, por exemplo, o Cavalo de Tróia seriam por isso ignoradas, só depois de ocorridos os factos reconheceu-se que teria sido sensato escutá-la. Mais do que apresentar alternativas, a essência do papel de Cassandra consiste em lançar avisos quanto às consequências previsíveis de certas linhas de ação (ou de inação), e quiçá até ver nelas uma armadilha a evitar: quando os decisores perguntam "mas qual é a alternativa que propõe?", o que normalmente isso subentende é uma alternativa que tenha por base as premissas deles, e que por sua vez, dada a lógica do "newspeak", será um alvo fácil de abater. Esta abordagem tende a basear-se numa avaliação das motivações dos dirigentes políticos feita mais a partir daquilo que é a sua ação efetiva do que das palavras que proferem. Se isto ainda não bastar para se fazer ouvir, entra também em ação a psicologia social da dissonância cognitiva: os atores que acham que têm boas razões para agir como agem tenderão igualmente a achar que essas ações produzirão bons efeitos - filtrando assim, à partida, as mensagens de sentido contrário. Acresce que quem se coloca no papel de Cassandra tem que produzir afirmações sobre o futuro, as quais não só são difíceis de avaliar a priori (Wiberg, 1976), como são algo que os padrões académicos tradicionais costumam evitar, pelo menos até que o futuro a que tais afirmações se refiram tenha já passado e as hipóteses nelas contidas tenham sido confirmadas - ou infirmadas.

Uma investigação para a paz orientada para políticas concretas é algo que pode, portanto, significar diferentes coisas e conduzir à assunção de diferentes papéis. Saber qual desses papéis é mais adequado depende, entre outras coisas, do conjunto de questões a investigar, da estrutura política e mediática do país do investigador ou investigadora, e daquilo que sua particular personalidade e competências sociais lhe permitam, ou não, fazer. A melhor oportunidade de disseminar a investigação para a paz talvez seja pelo menos alguns investigadores desempenharem a totalidade desses papéis. 
ANO 15 • NÚMERO 28 • 1은. 2018 • ORGANICOM

INVESTIGAÇÃO PARA A PAZ: PASSADO, PRESENTE E FUTURO

\section{O QUE OS INVESTIGADORES DA PAZ FAZEM EM CONCRETO}

Que uma coisa são as declarações programáticas e outra é a investigação efetivamente feita, eis uma verdade que não é menos válida no caso da investigação para a paz do que nas demais disciplinas. Daí que se imponha formular uma importante questão empírica: até que ponto a investigação para a paz, com a sua autoimagem reiteradamente configurada em termos de uma orientação para valores, se compagina com a realidade efetiva da investigação? A questão não é tão linear como pode parecer. Se quisermos saber quais as tendências do pensamento dos investigadores da paz, deveríamos proceder a inquéritos sociológicos para averiguar se estes consideram "a orientação no sentido de valores" ou a "relevância política" um ideal normativo - ou sequer uma descrição adequada. Se o que nos interessa é mais aquilo que eles efetivamente fazem, parece então que o que se impõe é levar a cabo uma análise de conteúdo daquilo que de facto é apresentado no âmbito dos congressos ou publicado nas revistas da especialidade - devendo, no entanto, proceder-se previamente a uma delimitação daquilo que são os estudiosos, os institutos, os congressos ou as publicações da "investigação para a paz". Contudo, mesmo que nos circunscrevamos às instituições que nitidamente se identificam com a investigação para a paz, como sejam a JPR ou a IPRA, estou plenamente convencido - ainda que carecendo de fundamento numa análise quantitativa - que a maioria das publicações existentes não tem, explicitamente, a ver com valores. Mas isso não põe termo à discussão. Com efeito, ficam ainda questões por colocar, dependendo de como definimos o problema. A orientação no sentido de valores pode ser implícita, e não propriamente algo de explicitamente formulado. Assim, pode por exemplo suceder uma determinada publicação surgir desprendida de valores, mas ao mesmo tempo ser parte integrante de um programa de investigação mais amplo e enformado por valores, que dela só estarão ausentes devido a uma eventual divisão do trabalho.

\section{A LUTA PELO TERRITÓRIO COGNITIVO}

A história das disciplinas académicas é marcada pelas sucessivas cisões e especializações daquilo que outrora foram a teologia, a filosofia, a medicina e o direito. As ciências naturais emanciparam-se da filosofia há alguns séculos, tendo-se depois dividido num número crescente de disciplinas; no que se refere às ciências sociais, este processo começou no século XIX ou mesmo no XX, tendo a génese das diferentes disciplinas variado ligeiramente entre os diversos sistemas académicos dos diferentes países e regiões. Em alguns casos, as ciências políticas nasceram diretamente da filosofia (por vezes com passagem pela "filosofia política"), noutros casos resultaram da fratura da história ou da estatística. Na sequência deste e de outros processos, temos hoje uma concatenação de áreas de investigação vagamente delimitadas, ou seja, todo um território cognitivo e quatro disciplinas que, em coligações mutáveis, por ele competem entre si: as ciências políticas, as relações internacionais, os estudos estratégicos e a investigação para a paz. A ciência política é a mais antiga; quanto às restantes, ou foram criadas a partir das ciências políticas, ou começaram "do zero". A primeira cadeira de relações internacionais foi criada em Aberystwyth após a I Guerra Mundial graças ao donativo de um Quaker que acreditava que uma melhor compreensão do sistema internacional seria capaz de torná-lo mais pacífico. Nalguns países existem cadeiras autónomas de relações internacionais, enquanto noutros as ciências políticas lograram manter a posse deste território. Fruto de decisões políticas ou de iniciativas da sociedade civil, criaram-se, em muitos casos, institutos de estudos estratégicos e de assuntos internacionais, normalmente fora do sistema universitário. Alguns dos institutos de investigação para a paz existentes nas universidades dos países nórdicos foram recriados inteiramente (e não através de subdivisões disciplinares). É o caso, por exemplo, da cadeira existente na Universidade de Oslo e dos departamentos existentes em Lund, Gotemburgo e Uppsala. Noutros casos, assistiu-se à criação de instituições independentes: o Instituto Internacional de Investigação para a Paz de Estocolmo (Stockholm International Peace Research Institute, SIPRI); o Instituto de Investigação para a Paz de Tampere (Tampere Peace Research Institute, TAPRI), posteriormente integrado na Universidade de Tampere; o PRIO, em Oslo; o Instituto Vida e Paz (Stiftelsen Liv- \& Fredinstitutet), em Uppsala; o Instituto de Investigação para a Paz de Copenhaga (Copenhagen Peace Research Institute, COPRI); a TFF, em Lund etc. 
Nalguns países e em determinados períodos, o grau de organização e o posicionamento das ciências políticas eram tais que Lhes permitiram reclamar a totalidade do território e impedir que qualquer outra tribo clamasse para si uma parcela. Noutros casos, só uma disciplina (as relações internacionais, os estudos estratégicos ou a investigação para a paz) conseguiu afirmarse com identidade própria. Nas situações de coexistência das disciplinas todas, assiste-se a coligações várias. Podemos ter situações de três contra um, a exemplo das ciências políticas contra os três restantes, irmanados no interesse comum que será a defesa de identidades separadas; ou podemos ter todos contra a investigação para a paz, sendo o interesse comum, nesse caso, a existência de paradigmas largamente coincidentes. Podem formar-se também coligações de dois contra dois, segundo os alinhamentos ideológicos ou com base em interesses comuns. Assim, e por exemplo, a investigação para a paz e os estudos estratégicos sempre tenderam, por tradição, a ter orientações claramente diferentes e até antitéticas, não obstante esse pendor ter passado a ser menos marcado a partir do momento em que uma e outros se viram intelectualmente postos em causa por Barry Buzan (1983). 0 facto de ambos tenderem a definir-se como "investigação aplicada" conferiuLhes - ao contrário do que sucede com as ciências políticas e as relações internacionais, "puramente académicas" - uma base de interesse comum, por um lado apostada em estabelecer critérios de qualidade fixos e caracterizados por uma neutralidade equidistante da investigação "aplicada", e por outro, da investigação "académica" ou "básica", que deste modo não sai favorecida.

Pode ser impossível dar definições não-ambíguas do território e dos subterritórios disputados pelas quatro disciplinas, até porque as respectivas pretensões variam com alguma frequência. No entanto, é possível apontar algumas linhas divisórias. Uma delas é a distinção entre nacional e internacional, com base na qual as relações internacionais tendem a reivindicar uma identidade própria, por sua vez frequentemente questionada pelas ciências políticas, que para si reclamam os dois lados dessa divisória. Dir-se-ia, nesse caso, que os estudos estratégicos estudavam o sistema internacional de uma perspectiva "nacional" (ou da perspectiva de uma aliança), enquanto a investigação para a paz o faria a partir de uma perspectiva internacional. Outra base para estabelecer distinções será definindo que tipos de instituições e de relações constituem 0 objeto de estudo: só as de natureza política (independentemente de como as definamos), ou um leque mais amplo? Incluímos apenas as relações e instituições que determinam a guerra e a paz, ou alargamos o âmbito? No primeiro caso, as relações internacionais poderão reivindicar uma identidade distinta das ciências políticas, com base no argumento do "alargamento de âmbito"; no segundo caso, as relações internacionais poderão reivindicar a totalidade do território da investigação para a paz (bem como dos estudos estratégicos), insistindo que as relações internacionais têm um âmbito mais vasto. 0 contraargumento da investigação para a paz poderá, nesse caso, ser o facto de cobrir um território que as relações internacionais não podem reivindicar para si: os conflitos, a paz e a guerra no interior dos espaços nacionais. Ou então poderá argumentar em sentido contrário, dizendo que, pelo facto de as relações internacionais terem um âmbito mais vasto, a investigação para a paz constitui uma especialização adequada - que é o mesmo argumento que as relações internacionais utilizam com relação às ciências políticas.

Qualquer exercício a que se proceda no sentido de cartografar este território acaba por deparar com complicações acrescidas. Em primeiro lugar, podemos guiar-nos pelas autodefinições abstratas das diferentes disciplinas - por aquilo a que "em princípio" elas se dedicam ou se propõem -, ou podemos proceder a um levantamento do tipo de investigação efetivamente levado a cabo nos diversos institutos. Em segundo lugar, colocam-se questões complexas quanto à interação entre fenómenos e relações de âmbito intra e internacional; as linhas de demarcação serão afetadas não só por eventuais desenvolvimentos políticos, mas também pelos novos resultados da investigação. Assiste-se a uma intervenção frequente e porventura crescente, por parte de outras nações, naquilo a que dantes se chamava guerras civis, e essa ligação pode ser utilizada pelas diferentes disciplinas na disputa que mantêm entre si. Estas batalhas em torno das definições tendem a surgir - ou a sofrer uma escalada - sempre que há território a (re)distribuir, a exemplo na sequência de relatórios governamentais ou aquando da criação de novas cadeiras ou de novos institutos. 
ANO 15 • NÚMERO 28 • 1ํㅗ․ 2018 • ORGANICOM

INVESTIGAÇÃO PARA A PAZ: PASSADO, PRESENTE E FUTURO

\section{PERSPECTIVAS DE FUTURO}

Para obteremos um quadro relativamente rigoroso da situação, comecemos pela vertente extrínseca, a das instituições e dos recursos, e limitemo-nos ao nordeste da Europa, pois uma abordagem deste tipo é preferível a uma análise forçosamente mais vaga de uma região mais vasta. Numa apreciação global, registaram-se nos últimos anos novos progressos na investigação para a paz. 0 balanço é totalmente positivo no caso da Noruega, com a criação em 2003, no âmbito do PRIO, de um Centro de Excelência com boas dotações financeiras e dedicado ao estudo dos diferentes tipos de guerra civil; a criação recente do Centro de Estudos para a Paz da Universidade de Tromsø; e os planos para a criação, na Universidade de Oslo, de uma nova cadeira relacionada à investigação para a paz. Na Suécia, foi criada uma segunda cadeira no Departamento para a Investigação sobre a Paz e os Conflitos na Universidade de Uppsala, e o número de candidatos ao novo programa de investigação para a paz e direitos humanos da Universidade de Malmö foi dezenas de vezes superior ao número de vagas disponíveis. Na Alemanha, 0 acontecimento de maior destaque foi a criação, há alguns anos, de um fundo de 50 milhões de marcos destinado a promover o estudo científico e o ensino da investigação para a paz nas universidades alemãs. Em 2004, a Universidade Estatal de São Petersburgo inaugurou um instituto de investigação para a paz. Pelo lado negativo, há a contabilizar a perda do estatuto de autonomia do TAPRI, na Finlândia, que passou a depender de um departamento universitário (mais um resultado tardio da segunda crise do que propriamente consequência da terceira), e o encerramento do COPRI em 2002, na sequência da chegada ao poder na Dinamarca, pela primeira vez em décadas, de um governo exclusivamente de direita (Copenhagen Peace Research Institute, 2002; Guzzini; Jung, 2004). Em termos puramente quantitativos, e não obstante estes reveses, a investigação para a paz na Europa do Norte encontra-se mais forte do que nunca, quer se use como medida o número de estudantes de licenciatura ou de pós-graduação, as teses de doutoramento, o número de funcionários, a totalidade dos recursos económicos empregues etc. Apesar de esta ser ainda a região com a mais elevada "densidade de investigação sobre a paz" da Europa, outros institutos têm surgido noutras regiões do continente, tanto a sudeste como entre os países latinos. É o caso, concretamente, do aparecimento de vários institutos em França, Itália, Espanha e agora, também, de um primeiro centro localizado na Universidade de Coimbra, em Portugal.

\section{A PAZ POR MEIOS PACÍFICOS}

Com a crescente institucionalização da investigação para a paz, é provável virmos a assistir a novos episódios da luta pelos territórios cognitivos, numa disputa em que as ciências políticas e as relações internacionais se apresentam como as principais candidatas. Há quem defenda que a investigação para a paz, sendo um produto da Guerra Fria, devesse, agora que esta chegou ao fim, ser também dada por encerrada (se bem que quem assim pense não tire idêntica conclusão, por exemplo, no que se refere à Organização do Tratado do Atlântico Norte, NATO). Há também quem defenda que ela devia fundir-se com as relações internacionais (mas mantendo a designação de "relações internacionais", não a de "investigação para a paz"). A disputa territorial e todo o debate envolvente hão de, sem dúvida, continuar. No conjunto do território cognitivo, há algumas áreas - por exemplo, a investigação quanto às causas da guerra - que são reivindicadas por várias disciplinas ao mesmo tempo. E aqui, a investigação para a paz e seus institutos defrontam-se frequentemente com o seguinte dilema: se a concorrência científica lhe não corre de feição, arrisca-se a ver os institutos encerrados, e se corre demasiado bem, arrisca-se a que estes se fundam com outros. Perante isso, ela pode necessitar de reforçar certas áreas de investigação para as quais consiga reclamar uma singularidade ou em que possua tradições firmadas. Uma opção que aí se coloca será regressar às origens da investigação para a paz, quando "a paz por meios pacíficos" era algo que estava ainda implícito, se não mesmo explícito, como vemos em Galtung (1996). As ideias então propostas no sentido de ultrapassar a Guerra Fria não passavam, seguramente, pela vitória militar de um dos lados sobre o outro, e quanto a esse ponto não havia grande desacordo. No decurso da primeira crise surgiram noções de "violência benigna" (isto é, de lutar contra os regimes opressivos e, por vezes, contra as grandes 


\section{ANO 15 • NÚMERO 28 • 1오. SEM. 2018 • ORGANICOM}

INVESTIGAÇÃO PARA A PAZ: PASSADO, PRESENTE E FUTURO

potências que os apoiavam), mas normalmente os protagonistas (de esquerda) abandonavam a investigação para a paz quando viam que não conseguiam, neste capítulo, influenciar de maneira significativa a comunidade de investigadores. Alguns dos argumentos contra essa influência podemos ir buscá-los à análise proposta por Gene Sharp em The politics of non-violent action (1973). Nesta obra monumental, Sharp sustenta que, mesmo nos casos em que tal violência é bem-sucedida, ela tende a deixar atrás de si uma pesada herança que consiste em passar a ver a violência como um instrumento político legítimo, seja por parte do novo regime, seja por parte de seus adversários.

Posteriormente, assistiu-se a novo desentendimento no seio da comunidade dos investigadores da paz, desencadeado pela dissolução da antiga Jugoslávia: de um lado estavam os que, munidos de argumentos diversos, se opunham à intervenção militar por parte das grandes potências, enquanto de outro perfilavam-se aqueles que, usando outros argumentos, não só apoiavam essa intervenção como até apelavam a que ela tivesse lugar. Algo de decisivo se passara desde os primeiros anos, quando a não violência tinha uma presença muito mais assídua na agenda, fosse na versão gandhiana de Galtung, fosse nos termos mais pragmáticos de Sharp, fosse nos termos clausewitzianos de Boserup e Mack (1975). De nenhum destes autores se pode dizer que fosse um pacifista radical, que de todo rejeitasse o uso da violência fosse em que circunstâncias fosse (como, de resto, nem com o próprio Gandhi ou com Luther King [1963] se verificou). A questão, bem diversa, é que as perspectivas de não violência eram de tal modo subestimadas - como subestimados eram os custos a longo prazo da violência -, que tal recurso, mais do que uma solução promissora, seria sobretudo visto como uma capitulação moral e intelectual.

Acresce que, desde então, é longa a lista dos exemplos de não violência bem-sucedida que vieram juntar-se aos casos clássicos tratados pelos autores anteriormente referidos. Deste modo, assistiu-se ao derrube de regimes opressivos de índole diversa em vastas regiões da Europa, assim como em vários países da América Latina, da Ásia e de outras zonas do mundo. A comunidade de investigadores europeus da paz tem feito muitíssimo pouco para estudar este vasto conjunto de casos com maior profundidade, para daí retirar ilações quanto ao futuro. Os estudos mais clássicos versam as formas de resistência não violenta na Dinamarca, na Noruega e nalguns outros países durante a II Guerra Mundial, e alguns desses trabalhos debruçam-se ainda sobre a derrota do golpe de 1961 na Argélia e a resistência vivida na Checoslováquia nos anos de 1968-1969. Desde então, surgiram estudos relativos ao processo polaco de aprendizagem da ação não violenta (Journal of Peace Research, 1982) e à libertação da Lituânia (Miniotaitè, 2002). É, porém, flagrante a escassez (pelo menos em língua inglesa) de análises relativas a todos os outros casos. Mesmo que nos restrinjamos à Europa e ao período posterior a esse primeiro caso de sucesso ocorrido em Portugal no ano de 1974, verificamos que a sociedade civil derrubou regimes autoritários na Espanha, na Grécia, na Polónia, na Alemanha de Leste, na Checoslováquia, na Hungria, na Bulgária, na Albânia, em muitas regiões da antiga União Soviética (incluindo a própria Rússia), e ainda na Sérvia e na Geórgia, facto que é, por isso mesmo, merecedor de uma atenção muito particular. Existe, enfim, muito material a estudar e a comparar.

Mas a noção de chegar à paz por meios pacíficos vai muito para além da ação não violenta. Data de há muito tempo a busca de alternativas à guerra ou à ameaça de guerra como parte do esforço para influenciar os regimes desviantes, e a ideia de sanções económicas cedo marcou a sua presença nos institutos de investigação para a paz (Galtung, 1967; Wallensteen, 1968), como de resto acontece ainda hoje (Wallensteen, 2000). 0 otimismo inicial teve que ser revisto quando se verificou que as sanções económicas eram muitas vezes contraproducentes, e além disso, bastante mais mortíferas para as populações civis do que propriamente uma guerra de grandes proporções (como se tornou notório no Iraque), pelo que todo o programa de investigação teve que ser refeito em conformidade.

Nos primeiros tempos da investigação para a paz, debateu-se a hipótese de uma abordagem ainda mais ampla: a criação de sistemas de paz. Tal debate foi muitas vezes teórico e normativo, mas tem-se assistido ao aumento crescente de casos empíricos passíveis de estudo. A região dos países nórdicos foi um dos primeiros exemplos disto, salientado em Karl Deutsch et al. (1957), que a este propósito usa a expressão "comunidade de segurança". 0 desenvolvimento de longo prazo 
do sistema era algo que se encontrava na agenda inicial da investigação para a paz dos países nórdicos (Wallensteen; Vesa; Vayrynen, 1973), havendo estudos recentes sobre o modo como o sistema conseguiu achar soluções pacíficas para uma longa lista de conflitos respeitantes a aspetos tão explosivos como as questões do território, da autonomia, da independência e da língua (Wiberg, 2000; Archer; e Joenniemi, 2003). Se os países nórdicos (e o antigo Benelux) constituíram um caso singular neste capítulo, a verdade é que já não o são: hoje em dia, a União Europeia parece ter se tornado, no contexto mais geral da Europa, um sistema de paz, no interior do qual ninguém espera que os eventuais conflitos, mesmo se graves, conduzam a ameaças militares internas - se bem que este aspeto da questão pareça ter atraído um escasso interesse no que concerne a investigação; ao mesmo tempo, assistimos também ao surgimento de sistemas de paz no Sul da Ásia e no hemisfério ocidental.

Deparamo-nos aqui uma vasta área de estudo, especialmente se para isso for convocada uma concepção multidimensional de paz. A ausência de guerra, ou mesmo de ameaça de guerra, não constitui senão um aspeto: resta ver que sistemas vão ao encontro dos outros valores constantes das concepções de paz e até que ponto, e quais as relações recíprocas entre este facto e a abolição dos meios militares na transformação dos respectivos conflitos internos.

Tradução de João Paulo Moreira.

\section{REFERÊNCIAS}

ALLAN, Pierre; GOLDMANN, Kjell (Eds.). The end of the Cold War. evaluating theories of international relations. Den Haag: Kluwer Law International, 1995.

ARCHER, Clive; JOENNIEMI, Pertti (Eds.). The Nordic peace. Aldershot: Ashgate, 2003.

ASPLUND, Johan. Teorier om framtiden. Stockholm: Liber, 1979.

BERGER, Peter Ludwig; LUCKMANN, Thomas. The social construction of reality: a treatise in the sociology of knowledge. Garden City: Doubleday, 1966.

BOSERUP, Anders; MACK, Andrew. War without weapons: non-violence in national defence. New York: Schocken, 1975.

BOULDING, Elise; PASSMORE, Robert; GASSLER, Robert Scott. Bibliography on world conflict and peace. 2.ed. Boulder: Westview, 1979.

BOULDING, Elise; VAYRYNEN, Raimo. Peace research: the infant discipline. In: ROKKAN, Stein (Ed.). A quarter century of international social science: papers and reports on developments, 1952-1977. New Delhi: Concept, 1979. p.48-58.

BUZAN, Barry. People, states, and fear. the national security problem in international relations. Brighton: Wheatsheaf, 1983.

CHATFIELD, Charles. International peace research: the field defined by dissemination. Journal of Peace Research, Thousand Oaks, v.16, n.2, p.163-179, 1979.

COPENHAGEN PEACE RESEARCH INSTITUTE. COPRl: final report, 1985-2002. Copenhagen: Copenhagen Peace Research Institute, 2002. v.40. 
DEUTSCH, Karl et al. Political community and the North Atlantic area: international organization in the light of historical experience. Princeton, NJ: Princeton University Press, 1957.

AN EDITORIAL. Journal of Peace Research, Thousand Oaks, v.1, n.1, p.1-4, 1964.

GALLIE, Walter Bryce. Essentially contested concepts. Proceedings of the Aristotelian Society, Oxford, v.56, p.167-198, 1956.

GALTUNG, Johan. On the effects of economic sanctions: with examples from the Case of Rhodesia. World Politics, Cambridge, UK, v.19, n.3, p.378-416, 1967.

. On the Eastern European social formations. In: PEACE RESEARCH INSTITUTE OSLO. Papers in English 1980. Oslo: PRIO, 1980. v.S-26/80.

Social cosmology and the concept of peace. Journal of Peace Research, Thousand Oaks, v.18, n.2, p.183-199, 1981.

. Peace by peaceful means: peace and conflict, development and civilization. Oslo: PRIO; Thousand Oaks: Sage, 1996.

GLEDITSCH, Nils Petter. Journal of Peace Research 1964-87. Oslo: PRIO, 1987.

GUZZINI, Stefano; JUNG, Dietrich. Contemporary security research and Copenhagen peace research. London: Routledge, 2004.

HOOK, Glenn; KAN, Hideki. Peace research in Japan. International Peace Research Association Newsletter, Leuven, v.21, n.2, 1983. Não paginado.

INTERNATIONAL PEACE RESEARCH ASSOCIATION. Proceedings of the International Peace Research Association Third Conference. Assen: Van Gorcum, 1970. v.1.

ISHIDA, Takeshi. Beyond the traditional concepts of peace in different cultures. Journal of Peace Research, Thousand Oaks, v.6, n.2, p.133-145, 1969.

JOURNAL OF PEACE RESEARCH: special issue: poles on Poland. Thousand Oaks: Sage, v.19, n.2, 1982.

KING JUNIOR, Martin Luther. Letter from a Birmingham jail. African Studies Center. University Of Pennsylvania, Philadelphia, 16 abr. 1963. Disponível em: <https://bit.ly/1cbkqyh>. Acesso em: 6 jun. 2018.

KODAMA, Katsuya. History of International Peace Research Association. Kamihama: IPRA, 2004.

KOPPE, Karlheinz. Der vergessene Frieden: Friedensvorstellungen von der Antike bis zur Gegenwart. Opladen: Leske+Budrich, 2001.

KOPPE, Karlheinz; REICHARDT, Wolfgang (Eds.). Geschichte der Friedensforschung: Einführung und ausgewählte Texte. Hagen: Fernuniversität, 1994.

MINIOTAITĖ, Gražina. Nonviolent resistance in Lithuania: a story of peaceful liberation. Boston: Albert Einstein Institute, 2002. 
MYRDAL, Gunnar. Value in social theory. a selection of essays on methodology. London: Routledge; Kegan Paul, 1958.

ORWELL, George. Nineteen eighty-four. a novel. London: Secker \& Warburg, 1949.

RICHARDSON, Lewis Fry. Statistics of deadly quarrels. Chicago: Quadrangle, 1960.

SCHARFFENORTH, Gerta; HUBER, Wolfgang (Eds.). Neue Bibliographie zur Friedensforschung. München: Kosel, 1973.

SHARP, Gene. The politics of nonviolent action. Boston: Porter Sargent, 1973. 3v.

TRITTMANN, Uwe; SCHMIDT, Hajo (Eds.). Kultur und Konflikt. Dialog mit Johan Galtung. Münster: Agenda, 2002.

TROMP, Hylke. Introduction: changing perspectives in peace research. In: UNITED NATIONS EDUCATIONAL, SCIENTIFIC AND CULTURAL ORGANIZATION. Yearbook of peace and conflict studies 1980. Westport: Greenwood, 1981.

UNITED NATIONS EDUCATIONAL, SCIENTIFIC AND CULTURAL ORGANIZATION. World directory of peace research and training institutes. Paris: Unesco, 2000.

VAN DEN DUNGEN, Peter. Varieties of peace science: a historical note. Journal of Peace Science, Thousand Oaks, v.2, n.2, p.239-257, 1977.

Foundations of peace research. London: Housmans, 1981.

WALLENSTEEN, Peter. Characteristics of economic sanctions. Journal of Peace Research, v.5, n.3, p.248-267, 1968.

Structure and war: on international relations, 1920-68. Stockholm: Rabén \& Sjogren, 1973.

. A century of economic sanctions. a field revisited. Uppsala: Department of Peace and Conflict Research of Uppsala University, 2000. v.65.

WALLENSTEEN, Peter; VESA, Unto; VAYRYNEN, Raimo. The Nordic system: structure and change, 1920-1970. Tampere: Tampere Peace Research Institute, 1973.

WEBER, Max. Wissenschaft als Beruf. München: Duncker \& Humblot, 1919a.

. Politik als Beruf. München: Duncker \& Humblot, 1919b.

WIBERG, Håkan. How is it possible to evaluate propositions about the future? In: SCHWARZ, Stephan (Ed.). Knowledge and concepts in futures studies. Boulder: Westview, 1976. p.121-161.

The peace research movement. In: WALLENSTEEN, Peter (Ed.). Peace research: achievements and challenges. Boulder: Westview, 1988. p.30-53.

. Introduction: peace research, the old, new and post-new agendas. In: BALÁZS, Judit; WIBERG, Håkan (Eds.). Changes, chances, challenges: Europe 2000. Budapest: Akadémiai Kiadó, 1995. p.1-24. 


\section{ANO 15 • NÚMERO 28 • 1은. 2018 • ORGANICOM}

INVESTIGAÇÃO PARA A PAZ: PASSADO, PRESENTE E FUTURO

The Nordic security community: past, present, future. In: HEURLIN, Bertel; MOURITZEN, Hans (Eds.). Danish foreign policy yearbook 2000. Copenhagen: DUPI, 2000. p.121-137.

. Roles of peace research. In: VESA, Unto (Ed.). Maailman tutkimisesta ja muuttamisesta: Festschrift for Jyrki Kakonen. Tampere: TAPRI, 2003. p.109-119.

WIEN, Barbara (Ed.). Peace and world order studies: a curriculum guide. New York: Institute for World Order, 1981.

Texto recebido em 08.04.2018 e aprovado em 22.05.2018. 